\title{
Negative effect of hepatitis in overall and progression-free survival among patients with diffuse large B-cell lymphoma
}

\author{
Mubarak M. Al-Mansour ${ }^{1,2^{*}}$, Saif A. Alghamdi ${ }^{2}$, Musab A. Alsubaie ${ }^{2}$, Abdullah A. Alesa ${ }^{2}$ and Muhammad A. Khan²
}

\begin{abstract}
Background: Hepatitis B virus (HBV) is one of the most prevalent and serious infections worldwide. HBV reactivation is a serious complication for lymphoma patients who are being treated with rituximab-containing regimen. Since the impact of HBV has not been fully evaluated on the prognosis of diffuse large B cell lymphoma $(\mathrm{DLBCL})$, this study examined the effect of the hepatitis infection on the progression-free survival (PFS) and overall survival (OS) in patients with DLBCL who received rituximab-containing chemotherapy.

Methods: This retrospective cohort study was conducted at Princess Noorah Oncology Center, Jeddah by reviewing all medical records of $172 \mathrm{DLBCL}$ diagnosed patients and recieved Rituximab-containing chemotherapy dated from January 2009 to February 2016.

Results: Out of 172 patients, 53 were found positive in hepatitis serology. The 12 of those were HBsAg-positive and 41 were HBcAb-positive. Hepatitis reactivation was observed in $1 \%$ of the patients (i.e., 2 out of 172) and both of them were HBsAg-positive. Thus, the risk of hepatitis reactivation among the HBsAg-positive patients was 17\% (i.e., 2 out of 12). The predicted 3-year PFS for HBsAg-positive and HBCAb-positive were $52 \%( \pm 8 \%)$, while $76 \%( \pm 4)$ for HBsAg-negative and HBCAb-negative patients. On the other hand, the predicted 3-year OS for HBsAg and HBCAbnegative group is $93 \%( \pm 3)$ while for HBsAg-positive and HBCAb-positive is $77 \%( \pm 7)$, respectively.
\end{abstract}

Conclusion: The present study demonstrated a low HBV reactivation rate of $1 \%$ exclusively in 2 patients with $\mathrm{HBs} A$ g-positive status diagnosed with DLBCL and receiving R-CHOP chemotherapy.

Keywords: Hepatitis B virus reactivation, Lymphoma, Diffuse large B-cell lymphoma

\section{Background}

Hepatitis B virus (HBV) is one of the most prevalent and serious infections worldwide. It is estimated that more than one third of the world population has been infected with HBV and one million die annually from HBV-related liver disease $[1,2]$. Therefore, HBV is considered a major health risk. HBV reactivation is a serious complication for lymphoma patients who are being treated with rituximab containing regimen [3-5]. The risk is higher for patients who are HBsAg-positive at presentation, and ranges from 26 to $53 \%$, while the risk

\footnotetext{
* Correspondence: drmubarak55@hotmail.com

${ }^{1}$ Princess Noorah Oncology Center, King Abdulaziz Medical City, Ministry of National Guard Health Affairs-Western Region (WR), PO Box 9515, Jeddah 21423, Kingdom of Saudi Arabia

${ }^{2}$ College of Medicine (COM), King Saud Bin Abdulaziz University for Health Sciences (KSAU-HS), Jeddah, Saudi Arabia
}

is approximately 2 to $20 \%$ for $\mathrm{HBcAb}$-positive patients [6-8]. While the risk of reactivation and the role of prophylactic antiviral were described in the literature, nevertheless, the impact of HBsAg-positive or $\mathrm{HBcAb}$-positive status on the DLBCL prognosis has not been fully evaluated. Hence, this study examined the effect of hepatitis infection on the progression-free survival (PFS) and overall survival (OS) in patients with DLBCL who received R-CHOP chemotherapy.

\section{Methods}

This retrospective cohort study was conducted at Princess Noorah Oncology Center, Jeddah by reviewing all medical records of patients diagnosed with DBCL between January 2009 and February 2016. Patients at the age of over 16 years with histopathologically proven

(c) The Author(s). 2018 Open Access This article is distributed under the terms of the Creative Commons Attribution 4.0 International License (http://creativecommons.org/licenses/by/4.0/), which permits unrestricted use, distribution, and reproduction in any medium, provided you give appropriate credit to the original author(s) and the source, provide a link to the Creative Commons license, and indicate if changes were made. The Creative Commons Public Domain Dedication waiver (http://creativecommons.org/publicdomain/zero/1.0/) applies to the data made available in this article, unless otherwise stated. 
$\mathrm{CD}^{2} 0^{+}$and received frontline Rituximab-containing chemotherapy were included for this study. Patients with primary central nervous system (CNS) lymphoma, and patients who did not completed the total cycles of chemotherapy or only received palliative chemotherapy were excluded. Three reviewers conducted the case identification and data capturing using a computerized datasheet. A total of 172 patients were then identified and became eligible for this study.

\section{Data collected}

The collected data includes patients' demographic information, performance status, International Prognostic Index (IPI) score. The datasheet also comprised of disease characteristics, including stage, B-symptoms bone marrow involvement, and site of extranodal involvement. A complete history of the chemotherapy course and follow-up were noted as well. Patients were analyzed before and after chemotherapy for HBV serology including hepatitis B surface-antigen (HBsAg), hepatitis B envelope-antigen (HBeAg), and hepatitis B core-antibody (HBcAb IgM and HBcAb IgG). Viral load (HBV-DNA), liver profile (alanine aminotransferase [ALT], aspartate aminotransferase [AST], and total bilirubin [TB] levels) were also obtained before and after the chemotherapy. Prophylaxis to HBV with Entecavir ( $0.5 \mathrm{mg}$ orally everyday) or Lamivudine (100 mg orally everyday) was started one week before the chemotherapy in patients with positive $\mathrm{HBsAg}$ and $\mathrm{HBcAb}$ and some patients with only positive $\mathrm{HBcAb}$, and was ended 6 months after completion of the chemotherapy regimen. Date of HBV reactivation and patients post treatment status were recorded.

\section{Statistical method}

Patients were categorized into HBsAg and/or $\mathrm{HBcAb}$-negative and HBsAg-positive and/or $\mathrm{HBcAb}$-positive groups. Patients characteristics and other variables were compared as follows. A student's $\mathrm{t}$-test was used for continuous variables between the two groups. A $X^{2}$ test was used for a category or ordinal variables. Fisher's exact test was used when a small sample size existed. Progression-free survival (PFS) and overall survival (OS) were estimated by using the Kaplan-Meier method [9]. PFS was defined as from the date of diagnosis to the date of relapse or the date of the last follow-up. OS was defined as from the time of diagnosis to the date of death from any cause or the date of the last follow-up. Survival curves differences were analyzed using the two-tailed log-rank test [10]. Univariate analysis by using Cox's proportional hazards model was utilized to determine risk factors that affect PFS. Variables significantly identified in univariate analysis were tested in multivariate anvalysis by using Cox's proportion hazard model. All statistical tests were two-sided, and a $P$ value $<0.05$ was considered statistically significant. Analyses were performed by use of the SPSS statistical package (IBM Corp., Released 2012, IBM SPSS Statistics for Windows, Version 21.0. Armonk, NY: IBM Corp).

\section{Definition of HBV reactivation}

The researchers define HBV reactivation as a 10-folds or more increase in the HBV-DNA when compared to baseline during rituximab-containing chemotherapy or within 1 year after the final course of chemotherapy. Hepatitis attributable to HBV reactivation is defined as a threefold or more increase in ALT above the normal range or an increase in ALT to more than $100 \mathrm{U} / \mathrm{L}[11,12]$.

\section{Results}

Patients characteristics

A total of 172 patients with biopsy proven DLBCL were identified. The median age was 58 years (18-85). Majority of patients were males (55\%). In addition, $70 \%$ were diagnosed with advanced stage III-IV, and B symptoms were seen in $52 \%$. Moreover, $77 \%$ of patients had ECOG performance status $0-2$, and high-intermediate to high risk international prognostic index (IPI) was noted in $27 \%$ of patients. Extranodal involvement was reported in $58 \%$. The most common sites of extranodal sites were liver $(16 \%)$, bone $(13 \%)$, lung $(11 \%)$, stomach $(9 \%)$, and bone marrow (9\%). CNS involvement was observed in $8 \%$. Majority of patients were treated with R-CHOP chemotherapy (89\%). Patients clinical characteristics are presented in Table 1.

\section{Hepatitis serology status}

Fifty-three of the patients were found positive in hepatitis. The 12 of those are HBsAg-positive and 41 are $\mathrm{HBcAb}$-positive patients.

The proportion of HBsAg-positive patients who were $\mathrm{HBcAb}$-positive was $7 \%(12 / 172)$, and the proportion $\mathrm{HBs}$ Ag-negative patients who were $\mathrm{HBcAb}$-positive was $26 \%(41 / 160)$.

\section{Type of prophylaxis}

At the time of the diagnosis, all HBsAg-positive patients $(n=12)$ were given antiviral therapy with either Entecavir $(n=9)$ or Lamivudine $(n=3)$. Among the 41 $\mathrm{HBcAb}$-positive, 28 patients received prophylactic antiviral therapy with either Entecavir $(n=17)$ or Lamivudine $(n=11)$, and 13 patients did not receive any prophylaxis therapy.

\section{Hepatitis reactivation}

Hepatitis reactivation was observed in 1\% (2 of 172 patients). Patients who developed hepatitis reactivation were HBsAg-positive. Thus, the risk of hepatitis 
Table 1 Clinical characteristics

\begin{tabular}{|c|c|c|c|c|c|c|c|}
\hline \multirow[t]{2}{*}{ Characteristic } & \multicolumn{2}{|c|}{ All Patients $(N=172)$} & \multicolumn{2}{|c|}{ HBsAg and HBcAb Negative $(n=119)$} & \multicolumn{2}{|c|}{ HBsAg or HBcAb Positive $(n=53)$} & \multirow[t]{2}{*}{$P$} \\
\hline & No. & $\%$ & No. & $\%$ & No. & $\%$ & \\
\hline \multicolumn{8}{|l|}{ Age, years } \\
\hline Median (range) & \multicolumn{2}{|l|}{$58(18-85)$} & \multicolumn{2}{|l|}{$57(18-85)$} & \multicolumn{2}{|l|}{$62(32-85)$} & 0.02 \\
\hline \multicolumn{8}{|l|}{ Age groups, years } \\
\hline$<60$ & 96 & 56 & 75 & 63 & 21 & 40 & \multirow[t]{2}{*}{0.004} \\
\hline$\geq 60$ & 76 & 44 & 44 & 37 & 32 & 60 & \\
\hline \multicolumn{7}{|l|}{ Sex } & \multirow[t]{3}{*}{0.17} \\
\hline Male & 95 & 55 & 62 & 52 & 33 & 62 & \\
\hline Female & 77 & 45 & 57 & 48 & 20 & 38 & \\
\hline \multicolumn{8}{|l|}{ Ann Arbor stage } \\
\hline । & 10 & 6 & 8 & 7 & 2 & 4 & \multirow[t]{4}{*}{0.60} \\
\hline$\|$ & 42 & 24 & 31 & 26 & 11 & 21 & \\
\hline III & 20 & 12 & 12 & 10 & 8 & 15 & \\
\hline IV & 100 & 58 & 68 & 57 & 32 & 60 & \\
\hline \multicolumn{8}{|l|}{ B symptoms } \\
\hline No & 82 & 48 & 58 & 51 & 24 & 45 & \multirow[t]{2}{*}{0.67} \\
\hline Yes & 90 & 52 & 61 & 49 & 29 & 55 & \\
\hline Performance status 2-4 & 84 & 49 & 53 & 45 & 31 & 58 & 021 \\
\hline \multicolumn{8}{|l|}{ Extranodal } \\
\hline No & 73 & 42 & 52 & 44 & 21 & 40 & \multirow[t]{2}{*}{0.61} \\
\hline Yes & 99 & 58 & 67 & 56 & 32 & 60 & \\
\hline \multicolumn{8}{|c|}{ Serum LDH > Normal International prognostic index } \\
\hline Low & 62 & 38 & 46 & 39 & 15 & 28 & \multirow[t]{4}{*}{0.10} \\
\hline Low-intermediate & 57 & 35 & 35 & 29 & 11 & 21 & \\
\hline High-intermediate & 30 & 18 & 23 & 19 & 14 & 26 & \\
\hline High & 15 & 9 & 15 & 13 & 13 & 24 & \\
\hline \multicolumn{8}{|l|}{ Liver cirrhosis } \\
\hline No & 170 & 99 & 118 & 99 & 52 & 98 & \multirow[t]{2}{*}{0.55} \\
\hline Yes & 2 & 1 & 1 & 1 & 1 & 2 & \\
\hline \multicolumn{8}{|l|}{ Baseline liver function } \\
\hline$A L T>U N L$ & 14 & 8 & 10 & 8 & 4 & 8 & 0.78 \\
\hline $\mathrm{AST}>\mathrm{UNL}$ & 8 & 5 & 6 & 5 & 2 & 4 & 0.53 \\
\hline Bilirubin $>U N L$ & 6 & 3.5 & 5 & 4 & 1 & 2 & 0.39 \\
\hline Type of prophylaxis & & & & & & & \\
\hline NO & 132 & 77 & 119 & 100 & 13 & 25 & \\
\hline Entecavir & 26 & 15 & 0 & 0 & 26 & 49 & \\
\hline Lamivudine & 14 & 8 & 0 & 0 & 14 & 26 & 0.00 \\
\hline Chemotherapy & & & & & & & \\
\hline $\mathrm{R}-\mathrm{CHOP}$ & 153 & 89 & 124 & 106 & 89 & 89 & 0.39 \\
\hline $\mathrm{R}-\mathrm{CVP}$ & 12 & 7 & 14 & 6 & 5 & 11 & \\
\hline R-CEOP & 3 & 2 & 2 & 3 & 3 & 0 & \\
\hline R-EPOCH & 4 & 2 & 0 & 4 & 3 & 8 & \\
\hline
\end{tabular}


Table 1 Clinical characteristics (Continued)

\begin{tabular}{|c|c|c|c|c|c|c|c|}
\hline \multirow[t]{2}{*}{ Characteristic } & \multicolumn{2}{|c|}{ All Patients $(N=172)$} & \multicolumn{2}{|c|}{ HBsAg and HBcAb Negative $(n=119)$} & \multicolumn{2}{|c|}{ HBsAg or HBcAb Positive $(n=53)$} & \multirow[t]{2}{*}{ P } \\
\hline & No. & $\%$ & No. & $\%$ & No. & $\%$ & \\
\hline \multicolumn{8}{|c|}{ Consolidation radiotherapy } \\
\hline Yes & 17 & 10 & 12 & 10 & 5 & 9 & 0.89 \\
\hline No & 155 & 90 & 107 & 90 & 48 & 91 & \\
\hline \multicolumn{8}{|l|}{ No. of cycles } \\
\hline Median & 6 & & 6 & & 6 & & 0.40 \\
\hline Range & $1-11$ & & $3-11$ & & $1-8$ & & \\
\hline
\end{tabular}

reactivation among the $\mathrm{HBsAg}$-positive was $17 \%$ (2 of 12 patients). None of the $\mathrm{HBcAb}$-positive patients developed hepatitis reactivation regardless of the prophylaxis therapy. Hepatitis reactivation occurred after R-CHOP chemotherapy in two patients. One patient received a total of 6 cycles R-CHOP chemotherapy and developed hepatitis reactivation after 6 months from the last cycle of chemotherapy, whereas the second patient received a total of 6 cycles R-CHOP chemotherapy and developed hepatitis reactivation one year after completion of R-CHOP chemotherapy. For the two patients, the only marker for $\mathrm{HBV}$ reactivation, which is HBV-DNA, was elevated greater than 10-folds from the baseline. None of the two patients developed hepatitis with increased liver enzymes. Both patients were on Entecavir therapy before initiation of chemotherapy. The first patient developed a relapsed disease three years after the completion of R-CHOP chemotherapy. He was treated with salvage chemotherapy ESHAP for 6 cycles, and he is in remission and alive. The second patient is in remission and alive. Both patients didn't experience any more episodes of HBV reactivation.

\section{Hepatitis reactivation risk factors}

Several clinical and treatment-related factors were tested to identify if theres any clinical significant difference between those who developed hepatitis reactivation $(n=2)$ and those who did not $(n=51)$, and all of them were not significant.

\section{Survival analysis}

The median follow time was 34 months. Out of 172 patients, 50 patients $(29 \%)$ had relapsed or progressive disease post primary therapy. Twenty seven patients were HBsAg-negative and $\mathrm{HBcAb}$-negative, and 23 patients were either $\mathrm{HBsAg}$-positive or $\mathrm{HBcAb}$-positive. Out of the 23 patients, 4 patients among the HBsAg-positive had relapsed and one patient had progressive disease. Out of the remaining 18 patients with $\mathrm{HBcAb}$-positive, six patients had relapsed disease and 12 patient had progressive disease. Thus, the risk of relapse or progression was $23 \%$ among the $\mathrm{HBsAg-negative/HBcAb-negative}$ patients (27/119). For HBsAg-positive or HBcAb-positive patients, the risk of relapse was $43 \%$ (23/53). Treatment outcomes are presented in Table 2.

The median PFS for all patients was not reached with an estimated 3-year rate of $70 \%( \pm 4 \%)$. The predicted 3-year PFS for HBsAg-positive and/or HBcAb-positive were $52 \%( \pm 8 \%)$. However, the predicted 3-year PFS was $76 \%( \pm 4)$ for HBsAg and HBcAb-negative patients. The median OS for the whole group likewise not reached, the predicted 3-year OS was 93\% $( \pm 3)$ and 77\% ( \pm 7$)$ for HBsAg and HBcAb-negative group and HBsAg-positive and/or $\mathrm{HBcAb}$-positive group, respectively. There was significant difference in PFS $(P=0.009$; Fig. 1$)$ or OS $(P=0.012$; Fig. 2) rates in HBsAg and HBcAb-positive patients as compared to $\mathrm{HBsAg}$ and $\mathrm{HBcAb}$-negative patients, respectively. Out of all patients, 16 patients have died, 7 patients in the HBsAg-negative and

Table 2 Treatment Outcomes

\begin{tabular}{|c|c|c|c|c|c|c|c|}
\hline \multirow[t]{2}{*}{ Outcome } & \multicolumn{2}{|c|}{ All Patients $(N=172)$} & \multicolumn{2}{|c|}{ HBsAg/HBcAb Negative $(n=119)$} & \multicolumn{2}{|c|}{ HBsAg/HBcAb Positive $(n=53)$} & \multirow[t]{2}{*}{$P$} \\
\hline & No. & $\%$ & No. & $\%$ & No. & $\%$ & \\
\hline \multicolumn{8}{|l|}{ Response } \\
\hline $\mathrm{CR} / \mathrm{PR}$ & 122 & 71 & 92 & 77 & 30 & 57 & 0.022 \\
\hline $\mathrm{PD} / \mathrm{RD}$ & 29 & 17 & 16 & 14 & 13 & 24 & \\
\hline Disease relapse & 21 & 12 & 11 & 9 & 10 & 19 & \\
\hline Predicted 3-year PFS ( \pm SE) & \multicolumn{2}{|c|}{$67 \%( \pm 4 \%)$} & \multicolumn{2}{|c|}{$76 \%( \pm 4 \%)$} & \multicolumn{2}{|c|}{$52 \%( \pm 8 \%)$} & 0.009 \\
\hline Death & 16 & 9 & 7 & 6 & 9 & 17 & 0.21 \\
\hline Predicted 3-year OS ( \pm SE) & \multicolumn{2}{|c|}{$88 \%( \pm 3 \%)$} & \multicolumn{2}{|c|}{$93 \%( \pm 3 \%)$} & \multicolumn{2}{|c|}{$77 \%$ ( \pm 7\%) } & 0.012 \\
\hline
\end{tabular}

Abbreviations: $C R / P R$ Complete response/partial response, $P D / R D$ Progressive disease/refractory disease 


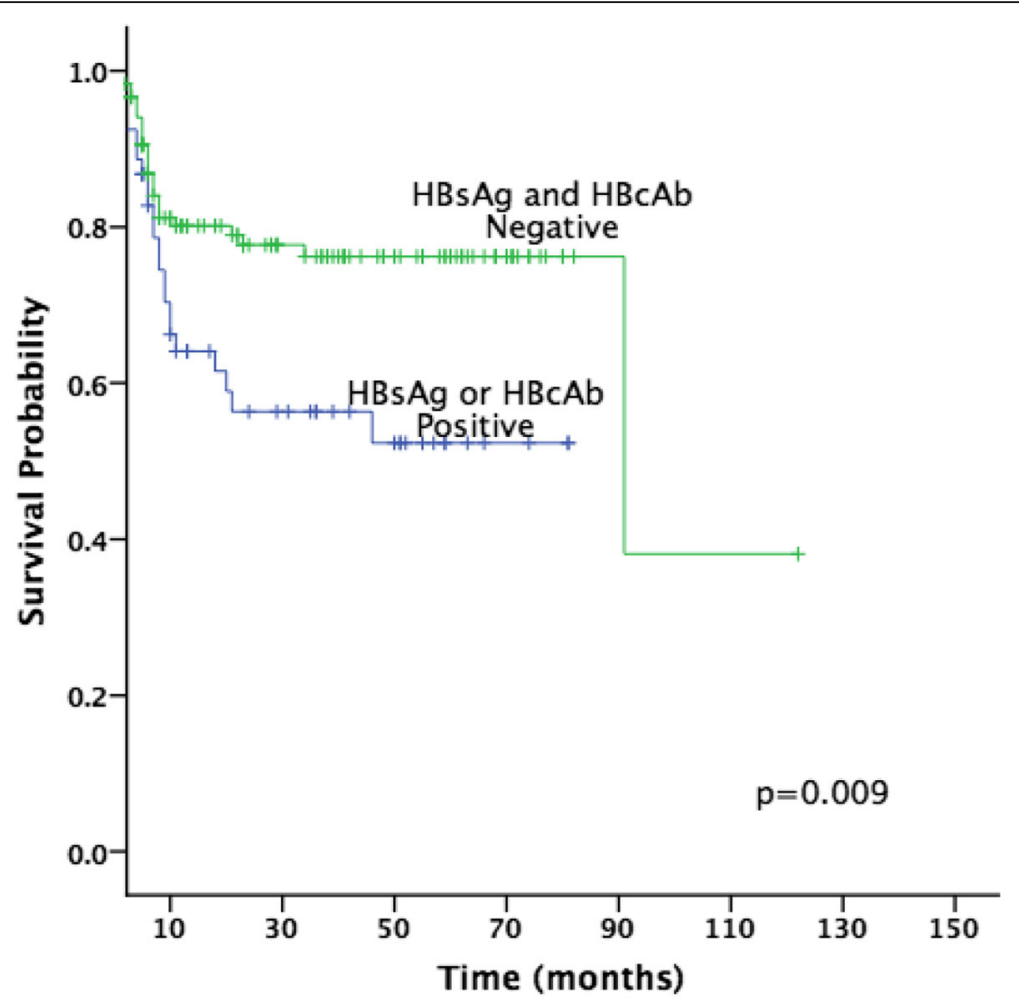

Fig. 1 Progression-free survival of HBsAg and HBCAb negative and HBsAg or HBCAb positive groups (two-sided $p=0.009$ )

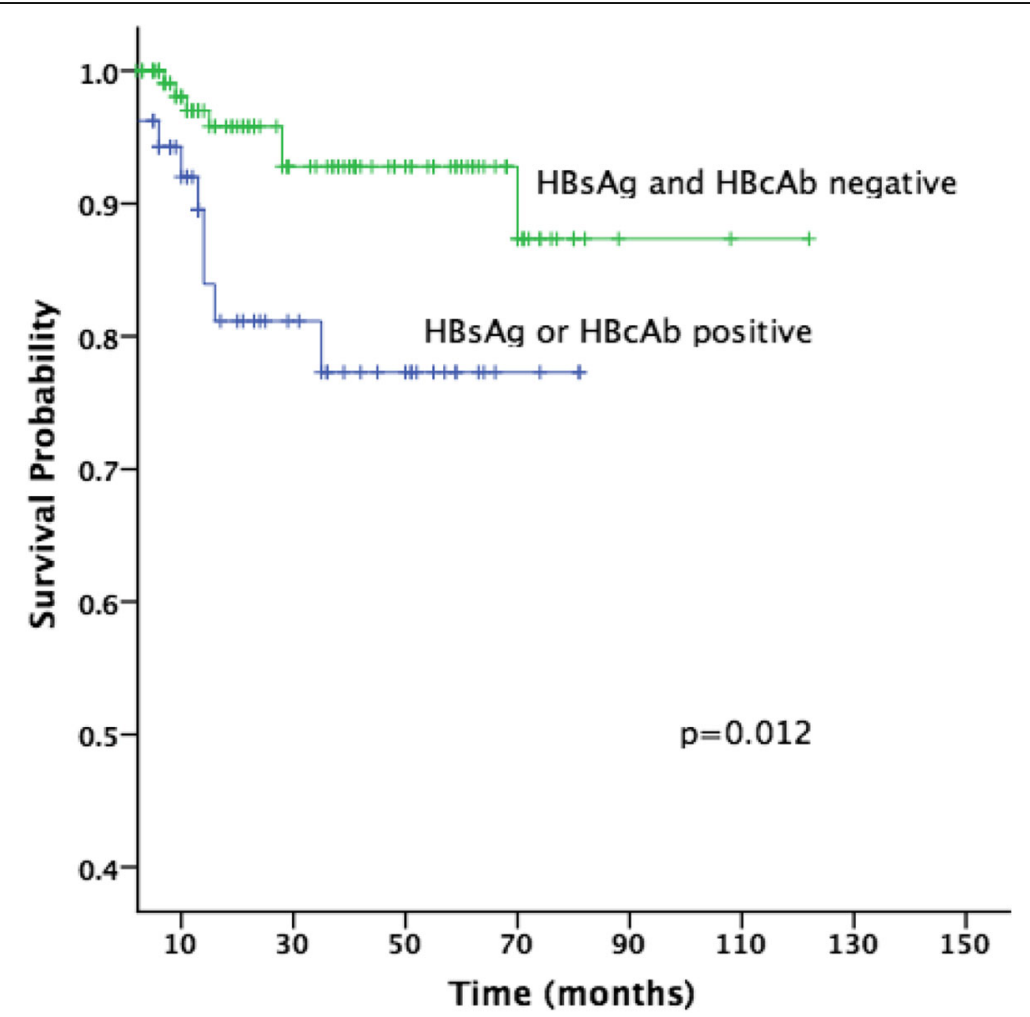

Fig. 2 Overall survival of $\mathrm{HBsAg}$ and $\mathrm{HBCAb}$ negative and $\mathrm{HBsAg}$ or $\mathrm{HBCAb}$ positive groups (two-sided $p=0.012$ ) 
$\mathrm{HBcAb}$-negative group, and 9 patients in the HBsAg-positive or HBcAb-positive group (Table 2).

In univariate analysis, clinical characteristics such as stage, IPI, extranodal involvement, poor performance status and $\mathrm{HBsAg}$-positive and/or $\mathrm{HBcAb}$-positive status were factors significantly affected the PFS. However, in multivariate analysis, $\mathrm{HBsAg}$-positive and/or $\mathrm{HBcAb}$-positive and poor performance status were the two independently factors that affected the PFS (HR $=0.55 ; 95 \% \mathrm{CI}: 0.31-0.99 ; p$ $=0.046)$ and $(\mathrm{HR}=1.65$; 95\%CI: $1.09-2.49 ; p=0.016)$, respectively. For OS, clinical factors such as stage, IPI, extranodal involvement, poor performance status and $\mathrm{HBsAg-positive} \mathrm{and/or} \mathrm{HBcAb-positive} \mathrm{were} \mathrm{also} \mathrm{found} \mathrm{to}$ be significant on univariate analysis. On multivariate analysis, the HBsAg-positive and/or HBcAb-positive status was the only factor independently affected the $\mathrm{OS}(\mathrm{HR}=0.32$; 95\% CI: 0.12-0.88; $p=0.028$ ).

\section{Discussion}

The prevalence of the chronic hepatitis infection (HBsAg-positive) in our patients with DLBCL was 7\%. This is lower compared to other reports from China where the prevalence of the chronic hepatitis infection in DLBCL patients ranges from 8.6 to $30.2 \%$ [13].

Among our patients with $\mathrm{HBsAg-negative,} \mathrm{the} \mathrm{preva-}$ lence of $\mathrm{HBcAb}$-positive was 26\%. Data from other countries demonstrated variable prevalence rate compared to our results. Some of those studies reported higher prevalence rate (34 to 44\%) of resolved hepatitis infection in DLBCL patients, and other studies showed lower rate ranging from 2 to $20.1 \%[13,14]$.

The risk of the hepatitis reactivation in our study was $1 \%$ for the whole group ( 2 out of 172 ). The two patients who developed hepatitis reactivation were HBsAg-positive at the time of the diagnosis with their lymphomas, and both received anti-viral treatment before initiation of the Rituximab based chemotherapy. This risk was similar to other studies in the Rituximab based therapy era. In addition, since HBV reactivation in our patients was observed 6 months to 1 year after the cessation of chemotherapy, several studies found out that cessation of rituximab-CHOP chemotherapy and antiviral such as lumivadine resulted in delayed HBV reactivation $[15,16]$. Thus, prophylactic antiviral therapy was recommended to extend to at least one year after discontinuation of chemotherapy [17].

There were no patients $(0 \%)$ who developed HBV reactivation in HBsAg-negative and HBcAb-positive group. This finding is consistent with the multicenter study conducted by Ji et al. [18] but in contrast with the result reported in the study of Yeo et al. (2.2 to 23.8\%) [19]. The discrepancy could be explained by giving prophylactic anti-viral therapy for $68 \%$ of our patients before initiation of chemotherapy. Other explanation could be the protective immunity for the previously resolved infection, which can be confirmed by the presence of the anti-hepatitis B surface antibody (HBsAb), but unfortunately this data is missing in our study.

In this retrospective study, we demonstrated a negative impact on PFS and OS in DLBCL patients with either HBsAg-positive or HBcAb-positive serology (Figs. 1 and 2). Despite the low risk of HPV reactivation, the risk of relapse was higher in HBsAg-positive and/or $\mathrm{HBcAb}$-positive group (43\%) as compared to HBsAg-negative and HBcAb-negative group (23\%), with a decrease in the 3 -year PFS from 76 to $52 \%$, and a decrease in the 3-year OS from 93 to $77 \%$ (Table 2). It is indeed that hepatitis infection is a significant factor that affects the survival of DLBCL patients. Although factors other than hepatitis infection were also described in literature, the exact mechanism and impact of these factors during chemotherapy remains unclear. This study, therefore, suggests to define recommendations and improvements on measures to prevent HBV reactivation among DLBCL patients.

\section{Limitations}

One of the limitations of the study was its retrospective nature in which we reviewed the charts of the patients. Moreover, the sample size was small and some of the data was not found in patients' charts like HBsAb which would have helped us in better result depiction.

\section{Conclusion}

The present study demonstrated a low HBV reactivation rate of $1 \%$ exclusively in two DLBCL patients with HBsAg-positive status. We have also demonstrated that HBV has an negative impact on the PFS and the OS of DLBCL patients. HBV reactivation in DLBCL patients receiving rituximab based chemotherapy in our study was less than what is reported in the literature.

\footnotetext{
Abbreviations

ALT: Alanine aminotransferase; ALT: Alanine Transaminae; AST: Aspartate aminotransferase; CR: Complete response; DLBCL: Diffuse Large B Cell Lymphoma; ECOG: Eastern Cooperative Oncology Group; ESHAP: Etopside, Solu-Medrol (Methylprednisolone), High-dose Ara-C (Cytarabine), Platinum (Cisplatin); HBCAb: Hepatitis B core-antibody; HBeAg: Hepatitis B envelopeantigen; HBsAg: Hepatitis B surface-antigen; HBV: Hepatitis B virus; HBVDNA: Hepatitis B Virus DNA; IgG: Immunoglobulin G; IgM: Immunoglobulin M; IPI: International Prognostic Index; OS: Overall survival; PD: Progressive disease; PFS: Progression free survival; PR: Partial response; R-

CEOP: Rituximab,Cyclophosphamide, Etoposide, Oncovin (Vincristine)

Prednisolone; R-CHOP: Rituximab, Cyclophosphamide, Hydroxydaunomycin (Doxorubicin Hydrochloride), Oncovin (vincristine), Prednisone; R-

CVP: Rituximab,Cyclophosphamide, Vincristine,Prednisone; RD: Refractory disease; R-EPOCH: Rituximab, Etoposide, Prednisone, Oncovin (Vincristine), Cyclophosphamide, Hydroxydaunorubicin (Doxorubicin Hydrochloride); TB: Total bilirubin; ULN: Upper Limit of Normal
}

Availability of data and materials

Please contact author for data requests. 


\section{Authors' contributions}

MMA carried out the conception and design of the study, analysis and interpretation, writing the manuscript, critical revision and assume the general responsibility and guaratees the scientific integrity of the study. SAA helped to draft the study, conducted the data collection, data analysis. MAA participated in data collection, statistics and data analysis. AAA participated in data collection and statistical analysis. MAK helped to draft and finalized manuscript, and performed the statistics and also data analysis. All authors read and approved the final manuscript.

\section{Ethics approval and consent to participate}

This study was approved by Institutional Review Board (IRB) of King Abdullah International Medical Research Center (KAIMRC), Jeddah, Saudi Arabia.

\section{Competing interests}

The authors declare that they have no competing interest.

\section{Publisher's Note}

Springer Nature remains neutral with regard to jurisdictional claims in published maps and institutional affiliations.

Received: 18 March 2018 Accepted: 30 May 2018

Published online: 07 June 2018

\section{References}

1. Pungpapong S, Kim WR, Poterucha JJ. Natural history of hepatitis B virus infection: an update for clinicians. Mayo Clin Proc. 2007 Aug;82(8):967-75.

2. Lee W. Hepatitis B virus infection. N Engl J Med. 1997;337:1733-45.

3. Yeo W, Chan PK, Zhong S, et al. Frequency of hepatitis B virus reactivation in cancer patients undergoing cytotoxic chemotherapy: a prospective study of 626 patients with identification of risk factors. J Med Virol. 2000;62(3):299-307.

4. Su WP, Wen CC, Hsiung CA, et al. Long-term hepatic consequences of chemotherapy-related HBV reactivation in lymphoma patients. World J Gastroenterol. 2005;11(34):5283-8.

5. Evens AM, Jovanovic BD, Su YC, et al. Rituximab-associated hepatitis B virus (HBV) reactivation in lymphoproliferative diseases: meta-analysis and examination of FDA safety reports. Ann Oncol. 2011;22(5):1170-80.

6. Yeo W, Zee B, Zhong S, et al. Comprehensive analysis of risk factors associating with hepatitis B virus (HBV) reactivation in cancer patients undergoing cytotoxic chemotherapy. Br J Cancer. 2004;90(7):1306-11.

7. Yeo W, Chan PK, Hui P, et al. Hepatitis B virus reactivation in breast cancer patients receiving cytotoxic chemotherapy: a prospective study. J Med Virol. 2003;70(4):553-61.

8. Lau GK, Yiu HH, Fong DY, et al. Early is superior to deferred preemptive lamivudine therapy for hepatitis B patients undergoing chemotherapy. Gastroenterology. 2003;125(6):1742-9.

9. Kaplan EL, Meier P. Nonparametric estimation from incomplete observations. J Am Stat Assoc. 1958:53:457-81.

10. Mantel N. Evaluation of survival data and two new rank order statistics arising in its consideration. Cancer Chemother Rep. 1966;50(3):163-70.

11. Lok AS, Liang RH, Chiu EK, et al. Reactivation of hepatitis B virus replication in patients receiving cytotoxic therapy. Report of a prospective study Gastroenterology. 1991;100(1):182-8.

12. Yeo W, Chan PK, Ho WM, et al. Lamivudine for the prevention of hepatitis B virus reactivation in hepatitis B s-antigen seropositive cancer patients undergoing cytotoxic chemotherapy. J Clin Oncol. 2004;22:927-34.

13. Marcucci F, Mele A, Spada E, Candido A, Bianco E, Pulsoni A, et al. High prevalence of hepatitis B virus infection in B-cell non-Hodgkin's lymphoma. Haematologica. 2006;91(4):554-7.

14. Wang $F, X u R H$, Han $B$, et al. High incidence of hepatitis $B$ virus infection in B-cell subtype non-Hodgkin lymphoma compared with other cancers. Cancer. 2007;109(7):1360-4

15. Perceau G, Diris N, Estines $\mathrm{O}$, et al. Late lethal hepatitis $\mathrm{B}$ virus reactivation after rituximab treatment of low-grade cutaneous B-cell lymphoma. Br J Dermatol. 2006;155:1053-6. 33

16. Dai MS, Chao TY, Kao WY, et al. Delayed hepatitis B virus reactivation after cessation of preemptive lamivudine in lymphoma patients treated with rituximab plus CHOP. Ann Hematol. 2004;83(12):769-74.
17. Law MF, Lai HK, Chan HN, et al. The impact of hepatitis B virus (HBV) infection on clinical outcomes of patients with diffuse large B-cell lymphoma. Eur J Cancer Care (Engl). 2015;24(1):117-24.

18. Ji $D$, Cao J, Hong $X$, et al. Low incidence of hepatitis $B$ virus reactivation during chemotherapy among diffuse large B-cell lymphoma patients who are HBsAg-negative/ HBCAb-positive: a multicenter retrospective study. Eur J Haematol. 2010;85(3):243-50

19. Yeo W, Chan TC, Leung NW, et al. Hepatitis B virus reactivation in lymphoma patients with prior resolved hepatitis B undergoing anticancer therapy with or without rituximab. J Clin Oncol. 2009;27(4):605-11.

\section{Ready to submit your research? Choose BMC and benefit from:}

- fast, convenient online submission

- thorough peer review by experienced researchers in your field

- rapid publication on acceptance

- support for research data, including large and complex data types

- gold Open Access which fosters wider collaboration and increased citations

- maximum visibility for your research: over $100 \mathrm{M}$ website views per year

At BMC, research is always in progress.

Learn more biomedcentral.com/submissions 